\title{
A SIMULATION STUDY ON THE RECONSTRUCTION OF COALMINE VENTILATION SYSTEM BASED ON WIND RESISTANCE CORRECTION
}

\author{
Song, Y. H. ; Guo, X. Y.**,\#; Lv, W. ; Guo, H. ${ }^{* *} \& \mathrm{Li}, \mathrm{R} . \mathrm{Y}^{* *}$ \\ *School of Management, Wuhan University of Technology, Wuhan, Hubei Province, P. R. China \\ ${ }^{* *}$ China Research Center for Emergency Management, Wuhan University of Technology, Wuhan, \\ Hubei Province, P. R. China \\ E-Mail: guoxinyao@ whut.edu.cn ( ${ }^{\#}$ Corresponding author)
}

\begin{abstract}
To accurately correct wind resistance acquisition problems during the ventilation reconstruction and then calculate the air quantity in various roadways, taking the reconstruction of ventilation system in Shaqu Coal Mine of China as an example, the "calculation-feedback-correction" mechanism for adjusting roadway wind resistance was proposed based on the Ventsim simulation technique. Wind resistance was calculated and the change of air supply-demand after the reconstruction of the ventilation system was analysed using the proposed mechanism. The reasonable isolation reconstruction program was verified. Finally, the relationship between opening area of air window and wind resistance after the isolation reconstruction was fitted by the Fluent technology and the optimal opening area of air window was calculated. Results show that: (1) the ventilator area of the south upcast inclined shaft $1 \#$ operates unstably after the isolation reconstruction; (2) when the opening area of air window reaches at least $3.28 \mathrm{~m}^{2}$, the ventilator works normally and steadily. The results also demonstrate that good ventilation effect can be achieved by adjusting resistance reduction and setting the optimal opening area of air window which conforms to the actual status of ventilation systems.

(Received in April 2016, accepted in November 2016. This paper was with the authors 2 months for 2 revisions.)
\end{abstract}

Key Words: Mine Ventilation, Ventilation System Reconstruction, 3D Ventilation System Simulation, Feedback Mechanism, Air Flow Short-Circuit Method

\section{INTRODUCTION}

Mine ventilation management plays an important role in safety mining production. The ventilation performance directly influences the production efficiency and economic efficiency of coal mines. Simulation of mine ventilation system refers to digitization of mine ventilation system. Based on simultaneous construction of the ventilator model and ventilation network topology, assignment of roadway characteristics in the ventilation network is calculated with computers to simulate the mine ventilation system [1]. Simulation of the ventilation system can achieve visualization of mine ventilation system and optimize the calculation method of the entire system to achieve the best system performance. Simulation of the ventilation system is supposed to be able to measure the wind resistance. However, wind resistance is generally measured by several effective roadways from the air intake to the air return instead of all roadways in the coal mine [2], so how to calculate or adjust wind resistance of unmeasured roadways effectively and make the simulation of ventilation system reflect actual ventilation situations accurately is a problem demanding prompt solution.

However, currently existing calculations of wind resistance in mine ventilation system based on computer simulation technology focus mainly on two-dimensional simulation of mine ventilation system [3]. With the advance of mining depth and width, the complexity of the mine ventilation system gradually increases. The $2 \mathrm{D}$ ventilation system map and its simulation neither can express the complicated spatial relation of roadways in the mine ventilation system nor ensure the consideration of the topological relation of roadways; thus, 
estimating wind resistance becomes inconvenient. Therefore, it is an inevitable tendency to explore the reconstruction and optimization of mine ventilation system by using the 3D visualization simulation technology [4]. Moreover, the ventilation system is required to be adjusted with the output growth and changes in exploitation layout because of continuous changes and developments in coal mine production [5]. In general, each local ventilation system network correlates with others, when adjusting or reconstructing the ventilation system, ensuring the normal ventilation in mines while keeping other ventilation regions safe during the damage of some ventilation nodes is technologically challenging for the reconstruction of ventilation system.

On this basis, the actual mine ventilation system was abstracted into a ventilation network model composed of branches, nodes, network topology structure, and corresponding attribute data in this study. Wind resistance of different roadways in the entire ventilation system was calculated by the data correction feedback mechanism based on independent local wind network. Then, the working state of main ventilator and the linear relationship between air window and wind resistance in the mine were analysed through computer simulation technology and adjustment of the air flow short-circuit method in ventilation network, aiming to find out the optimal reconstruction plan of mine ventilation system which conforms to practical production.

\section{STATE OF THE ART}

Considerable theoretical and practical studies on ventilation network simulation calculation, software development, and engineering application of mine ventilation system have been reported, particularly on wind resistance acquisition problems caused by dynamic changes in the reconstruction of mine ventilation system. Computer simulation technology of mine ventilation system plays the irreplaceable role in the change prediction and system design [69]. However, computer simulation technology requires accurate basic parameters in the mine ventilation system. Considering that mine ventilation system changes all the time, the wind resistance must be re-measured with the change in mine ventilation network structure. Therefore wind resistance is a basic parameter that is difficult to be determined in the ventilation system. The wind resistance of the coal mine is commonly used to replace the wind resistance of each roadway during the simulation analysis, and this method presents matching error with air quantity at main air-consumption points in practical ventilation system. How to acquire accurate and reliable wind resistance in ventilation simulation, the related scholars has been explored a lot. Cheng [10] developed an automatic wind resistance adjustment method, in which wind speed sensors were placed in roadways and ventilators to verify the state of mine ventilation system. Deen [11] calculated the wind resistance of mine shaft using the friction resistance coefficient from the theoretical and empirical equations. On the basis of the actual measurement and calculation analysis of the back propagation neural network model, Zhang [12] studied the ventilation resistance coefficient of roadways under the support of I-beams and increased the measurement accuracy. Si and Chen [13] proposed the optimal loop selection algorithm with few adjustments in the wind resistance calculation method according to dynamics and complexity of mine ventilation system. Moreover, they established wind resistance calculation model of mine ventilation network based on real-time dynamic monitoring data. $\mathrm{Li}$ et al. [14] aimed to solve the impossible measurement or inaccurate measurement of wind resistance in some roadways of the ventilation network and thus introduced the analytic calculation method of node pressure and calculated the wind resistance of roadways through inversion from air quantity. Deng and Liu [15] divided the total resistance of the one roadway and single ventilator into shaft resistance, heading end resistance, and uniform flow roadway resistance based on the computational fluid mechanism 
and basic principle of integrals. Existing related research estimates wind resistance mainly through artificial measurement and mathematical model. When simulating ventilation of the entire mine, much engineering load and considerable calculation load are required to calculate wind resistance or place the wind speed sensors of all roadways. This condition results in the large quantity and complex arrangement of mine roadways. Furthermore, a complicated and interacting topological structure is formed by crossing roadways. All of these conditions influence the measurement and calculation accuracy.

Recently, the calculation approach of mine ventilation networks has been used by scholars to calculate and verify wind resistance. The method mainly inputs relevant parameters (e.g., wind resistance and air quantity) into the computer simulation software and compares the air quantity output with the collected data, and then adjusted wind resistance of roadways closest to the actual situation is calculated while maintaining satisfying the accuracy of air quantity. With the VENTGraph simulation software and mathematical model for air flow, Dziurzynski et al. [16] compensated and balanced air quantity in determining the roadway pressure, and numerically investigated the optimization of mine ventilation network parameters. Li et al. [17] developed the decision-making system of deep mining safety control based on Longruan GIS and simulated mine ventilation system successfully to study ventilation system changes during deep coal production. Consequently, the mining safety and efficiency were increased. Wang et al. [18] established a mathematical model of smoke flow during fire accidents of coal mines. They also simulated smoke distribution characteristics in roadways by the Fluent software and achieved air quantity control and wind resistance adjustment by adjusting the area of ventilation door. Although these ventilation simulation software systems have been applied globally and achieved certain effect, they still present some shortcomings in actual mine ventilation management, such as system stability, high-efficiency operation, and intuitive and convenient interpretation of data analysis. In particular, the topology in the ventilation system has to be revised when the mine production layout changes. Selection of friction force and optimal wind resistance requires adequate experience of technicians. These systems have heavy working load and easily entail errors. Ventsim is one of the mostly used software systems in ventilation field to date and can effectively solve the $3 \mathrm{D}$ ventilation visualization, timeliness of ventilation network calculation, dynamic simulation of the ventilation process, and running stability. The system offsets the shortages of the abovementioned software systems in ventilation network calculation [19]. Develo et al. [20] conducted ventilation investigation of the Rosh Pinah Mine and found that the production plan moves toward the west gradually and the air quantity in west region is far lower than the standard. Through Ventsim simulation, they found that the ventilation reconstruction from the large ventilator in south region to the west region not only can meet ventilation requirements in the west region but also can reduce ventilation cost. The simulation verification proved significant effect of such ventilation reconstruction. Kim [21] simulated the ventilation network in improving the hot working environment in mine and pointed that increasing the shaft length and setting a ventilation door can increase $50 \%$ of the air quantity on the working face. Suvar et al. [22] conducted a simulation analysis on ventilation system in Lupeni Mine and Uricani Mine by use of the Ventsim software and through parameter setting of the mining engineering plan. They also calculated air quantity of different branches in ventilation system and proposed the optimization program. Considerable existing research mainly used the Ventsim software to calculate parameters of local ventilation system. However, simulating the entire mine ventilation system requires calculating the wind resistance of different local ventilation systems and considering their interaction comprehensively.

Therefore the feedback mechanism of data correction was proposed based on independence of local ventilation network in this study. With effective measurement data, air quantity of different roadways were compared with wind resistance of the local ventilation 
systems and wind resistance of other unmeasured roadways was adjusted. The ventilation state of the entire mine was truly reflected without influencing other local ventilation systems. Meanwhile, the isolation reconstruction of mine ventilation system was analysed by the Ventsim numerical simulation software. On one hand, the system solved technological difficulties, such as 3D visualization, immediacy of dynamic simulation, and running stability. On the other hand, the system realized simulation on wind pressure at fixed nodes and air quantity in branches as well as joint running local ventilators. Finally, the linear relationship between opening area of the air window and wind resistance was simulated and analysed using the Fluent software to achieve the optimal ventilation effect of mine.

\section{METHODOLOGY}

\subsection{Establishment of ventilation network model}

Ventilation system network is a complicated ventilation system. It is composed of several sub-systems, and each sub-system is formed by series-parallel connections of different local ventilation network systems. Although local ventilation network systems interact and influence mutually, they still exhibit independence in a local range.

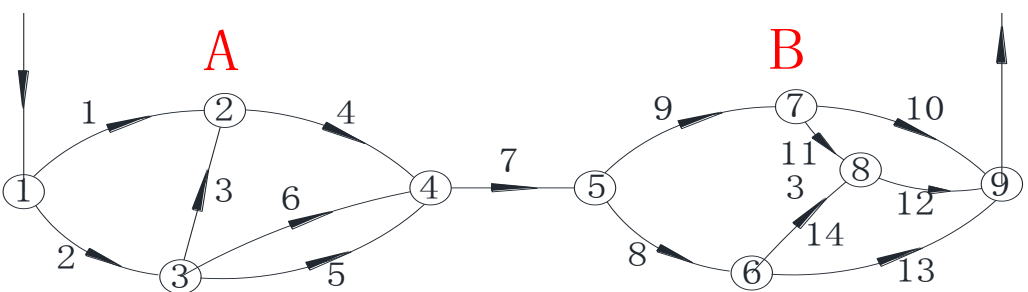

Figure 1: Simple ventilation network.

A simple ventilation network composed of 9 nodes and 16 branches is shown in Fig. 1. It is formed by series connection of two local ventilation network systems (A and B). Changes in wind resistance of roadways in system A only influences the total wind resistance of system A but do not influence system B. Changes in wind resistance of roadways in system B can only influence the total wind resistance of system B. This condition indicates that systems $\mathrm{A}$ and $\mathrm{B}$ are independent in structure to some extent. On this basis, the ventilation system simulation based on the feedback mechanism and the data correction method determined by wind resistance was proposed in this study. The main steps are as follows:

Firstly, the entire ventilation system was divided into several sub-systems according to main ventilation service ranges. Local ventilation network systems in every sub-system were determined. Secondly, relative pressures of main ventilation roadways in ventilation network sub-systems and roadways with ventilation control facilities were measured. The wind resistance of main roadways in the local ventilation network system and the total resistance of local ventilation network system were acquired. Thirdly, measured and calculated wind resistance data were input into the physical ventilation system model based on Ventsim software to calculate air volume of roadways. Data were corrected by comparing air quantity of roadways and wind resistance of local ventilation system network, adjusting wind resistance of other unmeasured roadways, and using the "calculation-feedback-adjustment" mechanism. Finally, all ventilation network sub-systems were connected and wind resistance of other connection roadways was adjusted simultaneously. As a result, the entire ventilation system could be balanced. The data correction flow is shown in Fig. 2.

Wind resistance in mine roadways was corrected and adjusted by the feedback mechanism based on Ventsim and corrected data were verified by simulation. When the error between the simulation results and measured results is no higher than $5 \%$, the used basic parameters of 
roadways and performance of the main ventilator conform to realities and could be used for simulation analysis of the mine ventilation reconstruction.

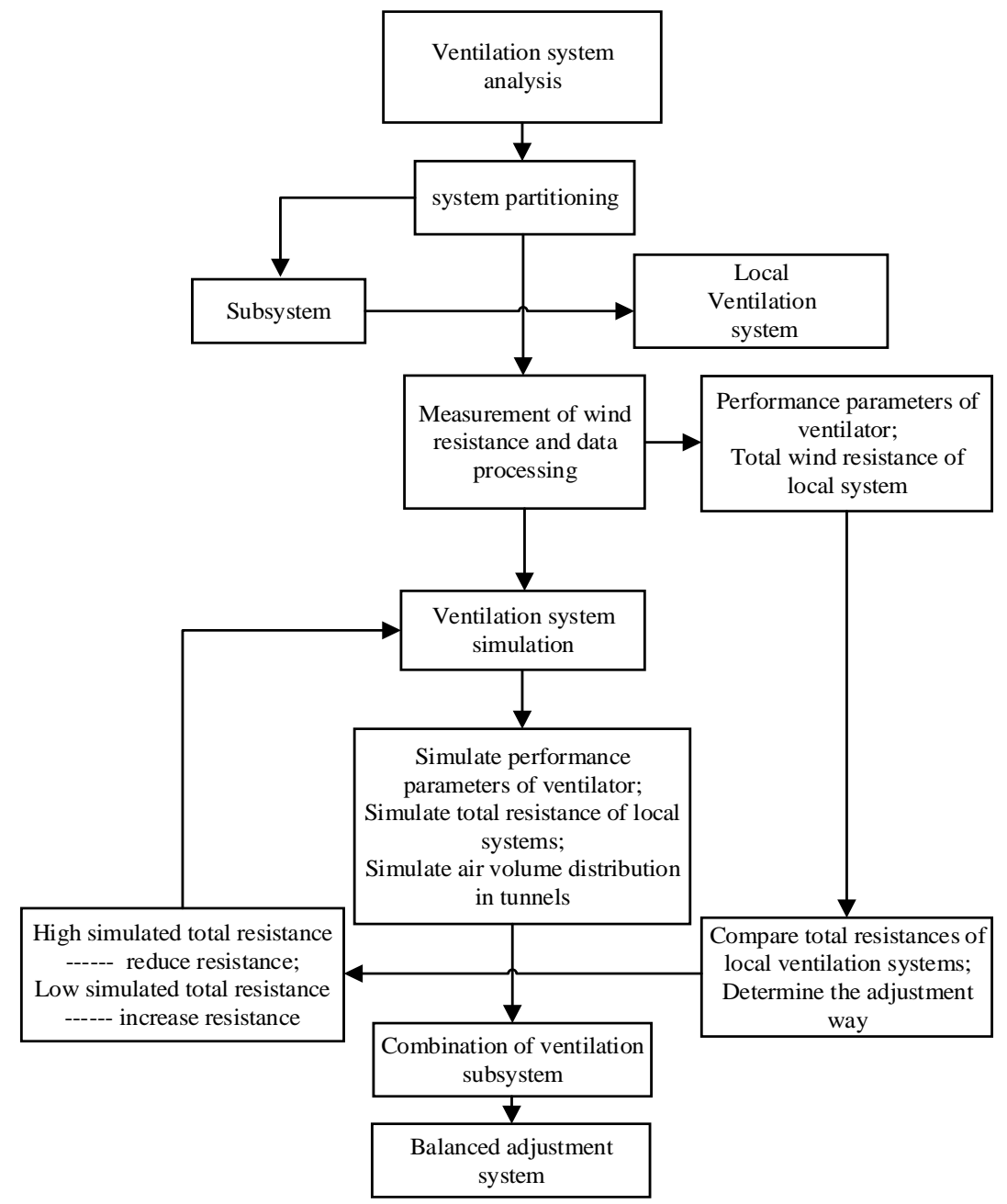

Figure 2: Data correction flow based on feedback mechanism.

The Ventsim mathematical model gains the iterative equation - Eq. (4) to solve wind pressure at nodes and air quantity at branches from the wind pressure balance equation - Eq. (1) and air quantity balance equation of nodes - Eq. (2) as well as the hypothesis linear wind resistance - Eq. (3).

$$
\begin{gathered}
\sum_{j=1}^{B} \alpha_{k j} Q_{j}=0, k=1,2, \ldots, N-1 \\
\sum_{i=1}^{N-1} \alpha_{i j} p_{i}=R_{j} Q_{j}\left|Q_{j}\right|-H_{f j}-H_{e j}, k=1,2, \ldots, B \\
C_{j}=1 /\left|R_{j} Q_{j}{ }^{0}\right|, j=1,2, \ldots, B \\
\sum_{i=1}^{N-1} \sum_{j=1}^{B} \alpha_{i j} \alpha_{k j} C_{j} p_{i}=-\sum_{j=1}^{B} C_{j} \alpha_{k j}\left(H_{f j}+H_{c j}\right), k=1,2, \ldots, N-1
\end{gathered}
$$

Eq. (4) is simplified as

$$
\sum_{i=1}^{N-1} x_{k i} p_{i}=y_{k}, k=1,2, \ldots ., N-1
$$

Eq. (5) is the mathematical model of linear solution and realizes optimization of the mine network through network adjustment in iterations. 
In Eq.(5), $Q_{j}^{0}$ is air quantity of the branch $j\left(\mathrm{~m}^{3} / \mathrm{s}\right) ; \alpha_{i j}$ is element at the row $i$ and column $j$ in the association matrix $\mathrm{A} ; R_{j}$ is wind resistance of the branch $j\left(\mathrm{NS}^{2} / \mathrm{m}^{8}\right) ; p_{i}$ is wind pressure at node $i(\mathrm{~Pa}) ; H_{f j}$ is the ventilation power of branch $j(\mathrm{~Pa}) ; H_{e j}$ is the ventilation differential pressure of branch $j(\mathrm{~Pa})$.

According to current main mining roadway and the elevation of working face in the Shaqu Coal Mine, as well as elevation data at measure points in the mine wind resistance test report, the spatial relation of different roadways were determined. On the basis of the $3 \mathrm{D}$ ventilation system model, geometric parameters of roadways and ventilation buildings were set and a 3D spatial structural model of ventilation system consistent with current ventilation system was formed. The simulation model is shown in Fig. 3.

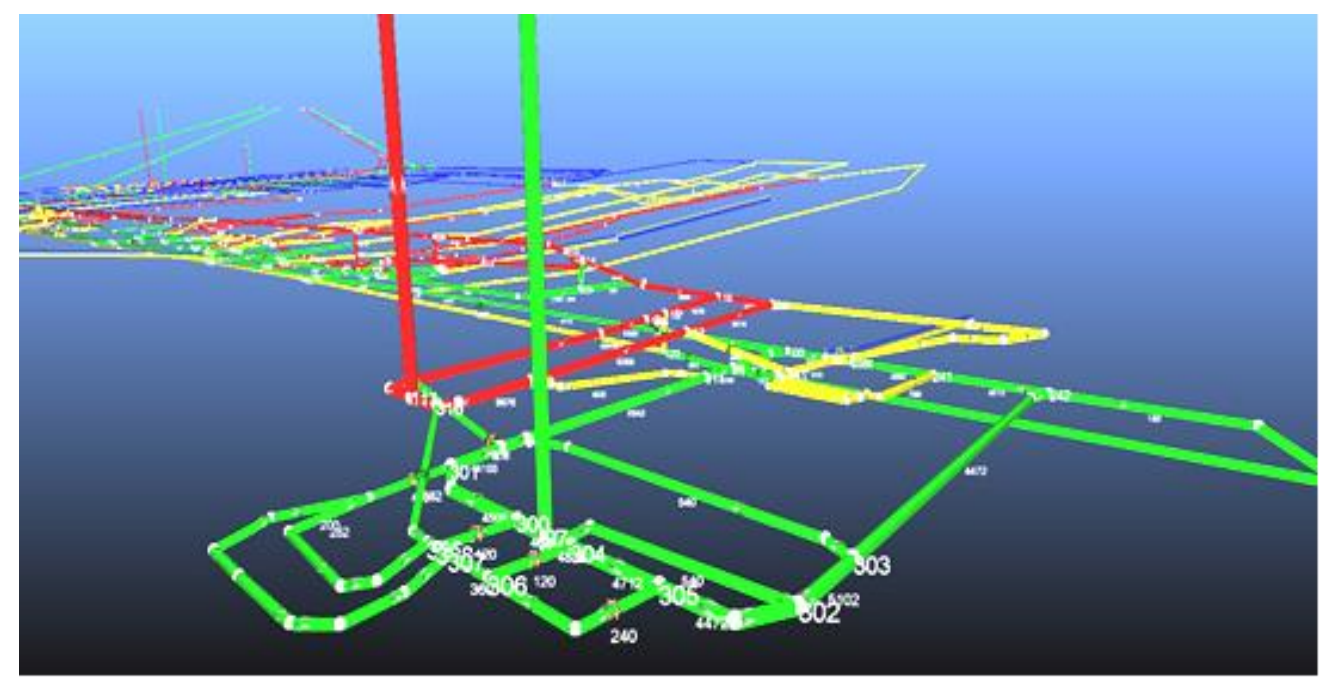

Figure 3: 3D mine ventilation model.

Association attributes of roadways in the ventilation system simulation model were assigned and error data of air quantity was processed by the "calculation-feedbackadjustment" mechanism; accordingly, the simulated results of air quantity of main ventilators in the mine were obtained (Table I). Table I shows that the current air quantity of ventilation system, running state, and measurement are consistent. Therefore, the 3D ventilation system model based on Ventsim can truly reflect air quantity of current mine ventilation system.

Table I: Simulated air quantity and measured air quantity of main ventilators.

\begin{tabular}{|c|c|c|c|c|}
\hline Roadway & Xialonghuayuan & Gaojiashan & 1\# return inclined shaft & Baijiapo \\
\hline Measured Air Quantity $\left(\mathrm{m}^{3} / \mathrm{s}\right)$ & 144.4 & 251.8 & 107.6 & 136.6 \\
\hline Simulated Air Quantity $\left(\mathrm{m}^{3} / \mathrm{s}\right)$ & 140.8 & 249.9 & 105.0 & 136.8 \\
\hline
\end{tabular}

\subsection{Ventilation system reconstruction project}

The Shaqu Mine includes mines 1\# and 2\#. Five interconnecting roadways were placed under mines 1\# and 2\# in accordance with the mining engineering plan of Shaqu Mine at present to prevent water burst or gas explosion of one mine influencing the safety production of the other mine. According to the waterproof requirements of settings, five closed waterproof gates were set in the five roadways. The shaft station was divided into mine $1 \#$ to ensure integrity of the two-mine ventilation system after isolation reconstruction. Considering the problems of water seepage and ponding in roadways, the waterproof gate should be closed at end of the roadway bottom with high elevation to finally form the isolation program of the reconstruction project (Fig. 4). 


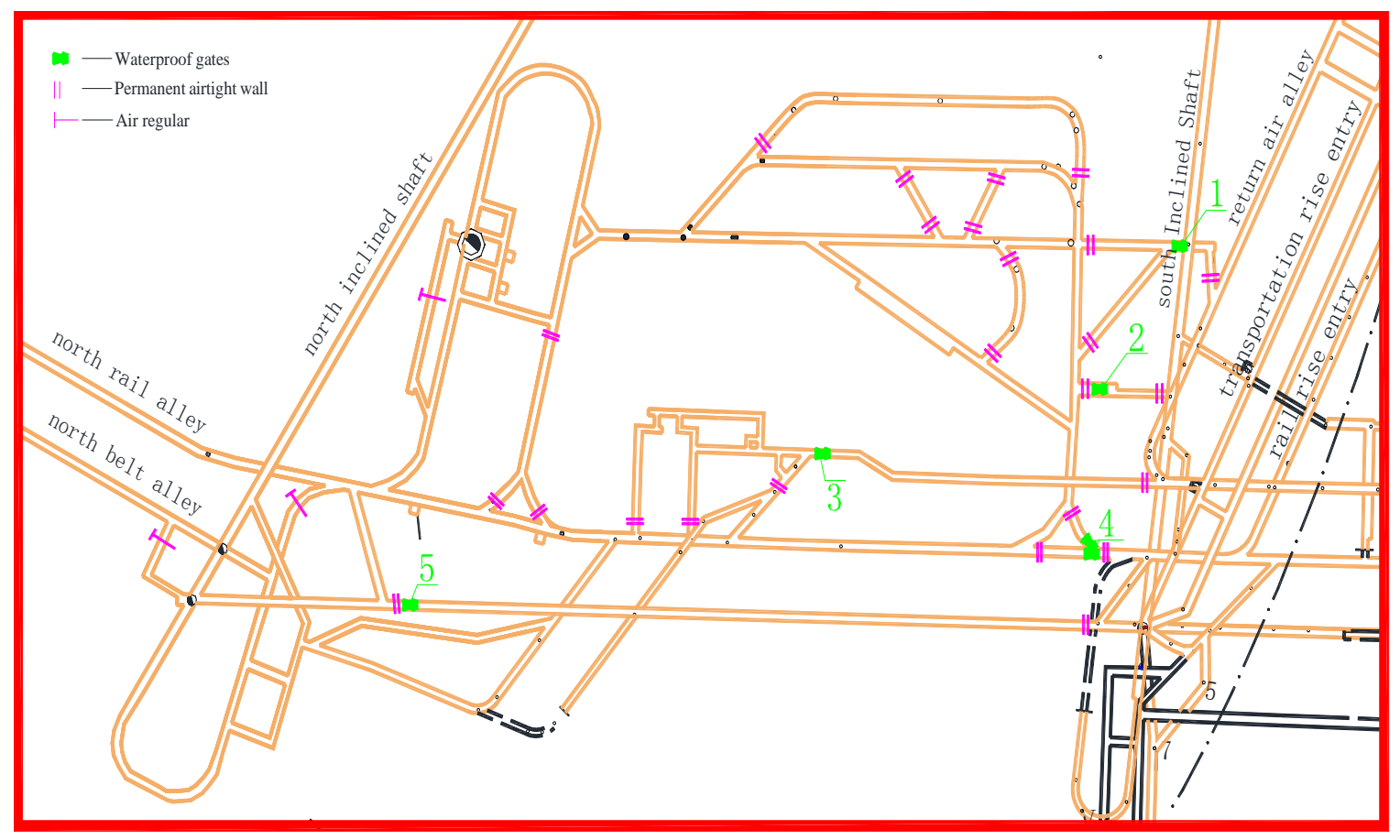

Figure 4: Isolation reconstruction project of the ventilation system.

In the isolation reconstruction project in Fig. 4, five groups of waterproof gates were set in the shaft bottom, the connected the rise of return airway in coal district 1 of mine $2 \#$, the south return airway, the south rail roadway, and the south belt roadway. Fire dams were set in the blind lane of shaft bottom and roadways with the wind speed lower than $0.25 \mathrm{~m} / \mathrm{s}$. Before isolation, mine \#2 supplied air to the south wing through the north main rail roadway and the air supply was $4600 \mathrm{~m}^{3} / \mathrm{min}$. After isolation, the vice mine in the north wing could not supply air to the south wing and air in the south wing was supplied by downcast inclined shaft $2 \#$ completely. This setting increases the air intake route length of the south wing, thereby the resistance of the ventilation system in the south wing increased.

According to the simulation model of the 3D ventilation system before the isolation and specific position of water dam in the reconstruction project, ventilation sealed walls should be set in the 3D ventilation system simulation model after the reconstruction (Fig. 5).

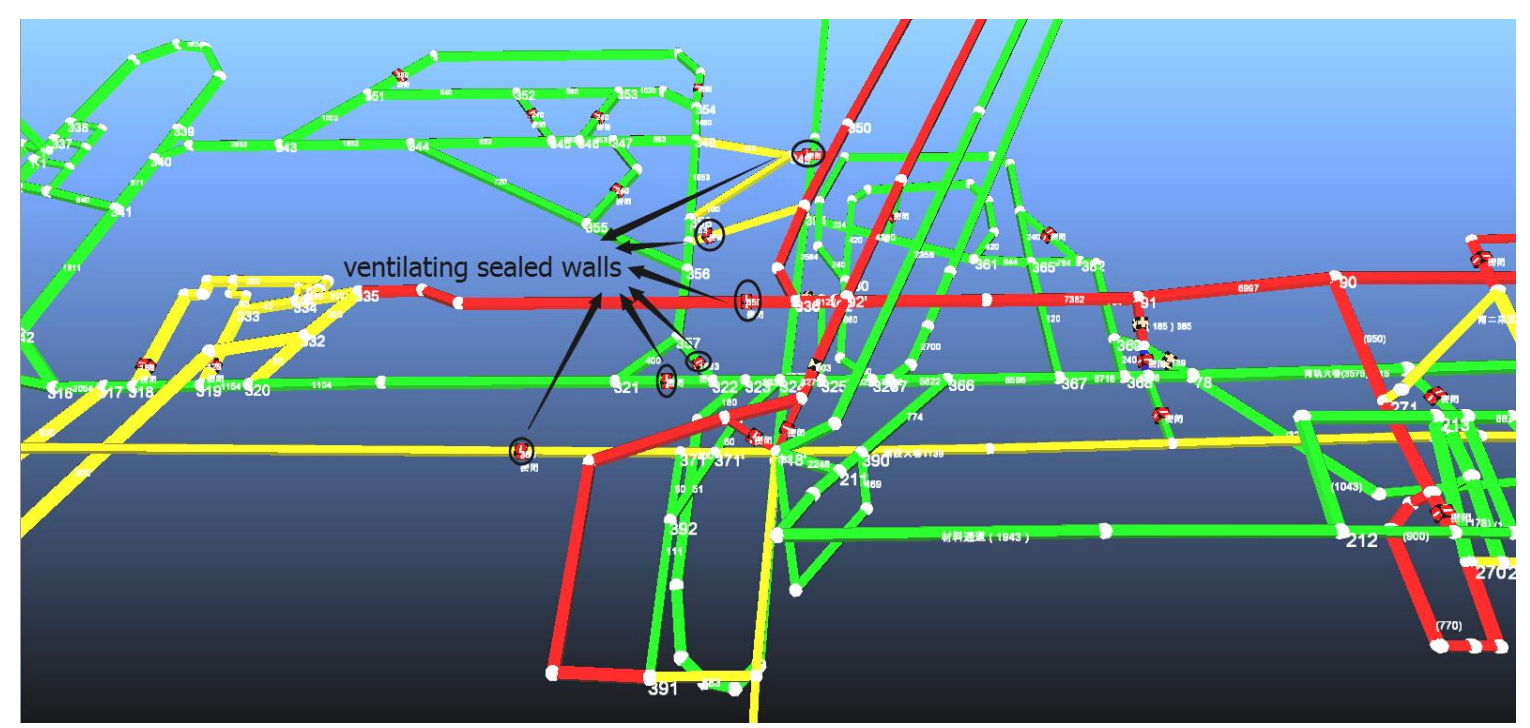

Figure 5: Isolation program. 


\subsection{Determination of the air window area}

The isolation reconstruction of mine ventilation system was implemented to surely change air quantity in the ventilation system. Wind resistance in roadways should be increased or decreased accordingly to ensure the stable state of ventilation system after the isolation reconstruction. Air window in the return airway can adjust the resistance of the ventilation system effectively. Different opening areas of air window cause different wind resistances. In this study, the relationship between the opening area of air window and wind resistance in the return airway was studied by the Fluent software. Thus, the optimal opening area of the air window for achieving the best ventilation effect was determined. The roadway section is a standard semicircular arch. The width and waist height of this semicircular arch are 4 and $3 \mathrm{~m}$, respectively. The air window is at the right of roadway, and the simulation model is shown in Fig. 6.

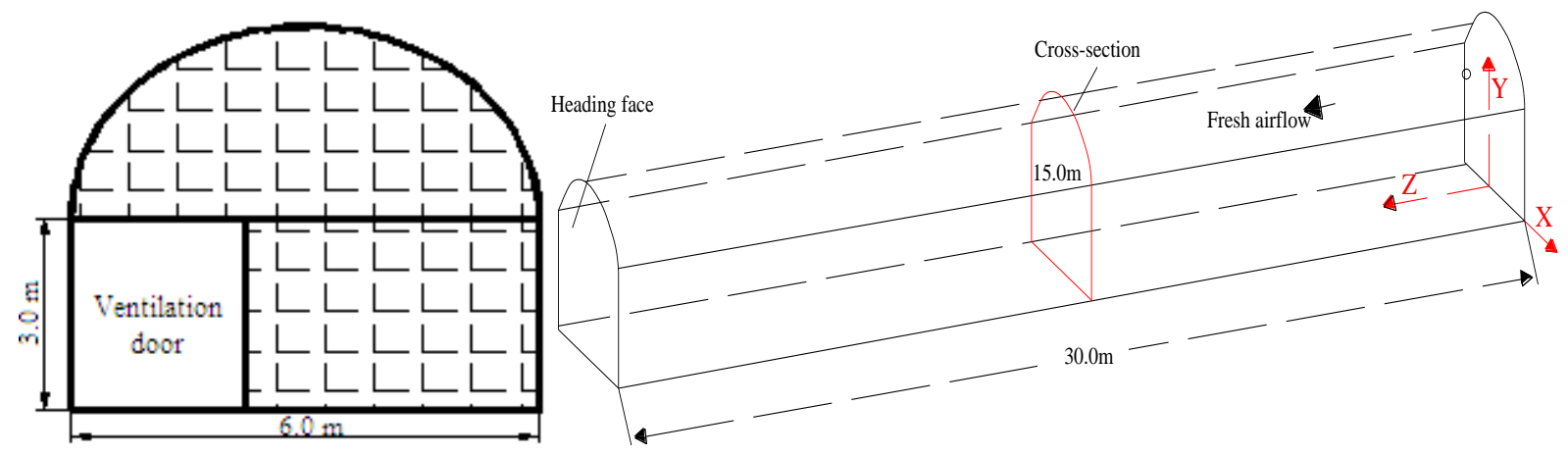

Figure 6: Geometric characteristics of the roadway and ventilation door.

In the mine, gas is at the low-Mach number flow state and could be viewed as the incompressible state. Gas obeys the mass conservation law during the flow process and is controlled by the continuity equation. The continuity equation of gas flow in the rectangular coordinate system could be expressed as

$$
\frac{\partial \rho}{\partial t}+\nabla(\rho u)=0
$$

For steady flow, $\frac{\partial \rho}{\partial t}=0$. The continuity equation is changed into $\nabla(\rho u)=0$.

In accordance with the summation agreement, the above equation is rewritten as

$$
\frac{\partial\left(\rho u_{i}\right)}{\partial x_{i}}=0
$$

The equation above expresses that the mass flow in unit volume space in unit time is equal to the mass of this volume space. In other words, the fluid mass in the micro-control volume does not change with time.

The air flow in the roadway is at the complete turbulent condition and conforms to the Maelstrom turbulent model. The turbulent kinetic energy equation $\mathrm{k}$ could be expressed as

$$
\frac{\partial}{\partial t}(\rho k)+\frac{\partial}{\partial x_{i}}\left(\rho k u_{i}\right)=\frac{\partial}{\partial x_{j}}\left[\left(\mu+\frac{\mu t}{\sigma k}\right) \frac{\partial k}{\partial x_{j}}\right]+G_{k}+G_{b}-\rho_{e}-Y_{M}+S_{k}
$$

Where $G_{k}$ is the turbulent kinetic energy caused by laminar velocity gradient (J); $G_{b}$ is the turbulent kinetic energy caused by buoyancy force $(\mathrm{J}) ; Y_{M}$ is fluctuation caused by transition diffusion in the compressible turbulent flow; $C_{1}, C_{2}$, and $C_{3}$ are constants; $\sigma_{k}$ is the turbulent Prandtl number of $k$. 


\section{SIMULATION RESULTS ANALYSIS}

After analogue computation, air quantity in main inclined shaft $1 \#$ and vice shaft decreased after the isolation reconstruction project. The working conditions of two ventilators in the north wing are kept constant meanwhile air quantity in the north rail roadway and north belt roadway increased by $1200 \mathrm{~m}^{3} / \mathrm{min}$. Therefore, the shaft bottom can meet the requirements of air quantity of roadway completely after the isolation reconstruction through adjustment in local air window, while air quantity at other air-consumption points changed slightly.

Because of the increase of the wind resistance in the south wing, working conditions of main ventilators and air quantity change at the main air-consumption points should be analysed. Comparison of working curves of ventilators in upcast inclined shaft $1 \#$ before and after the isolation is shown in Fig. 7.

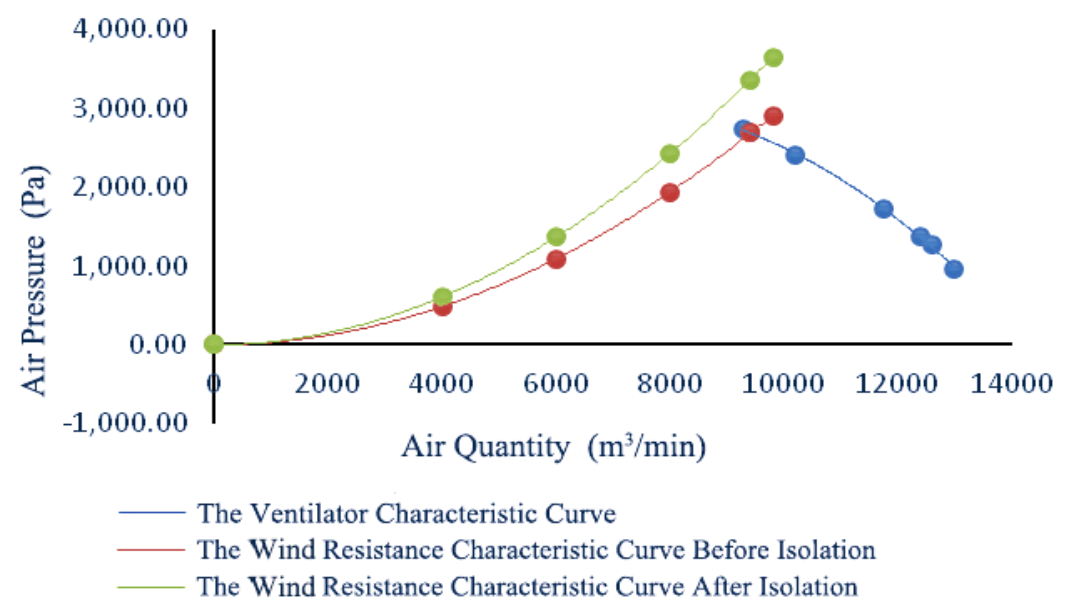

Figure 7: Comparison of working curves of ventilators in upcast inclined shaft $1 \#$.

The simulation results demonstrate that the resistance characteristic curve of mine $2 \#$ and the ventilator characteristic curve do not form an intersection after the isolation, indicating that the main ventilator in upcast inclined shaft $1 \#$ is at an unstable state at present, while the main ventilator in Baijiapo is at good working conditions. Air quantity of inclined shaft $2 \#$ in the south wing, the Shaqu downcast inclined shaft and the downcast shaft at Baijiapo increases to some extent. Such air quantity growth cannot compensate and isolate air supply to the north wing prior the isolation but can meet actual air demands through resistance reduction.

The unstable working state of ventilator in upcast inclined shaft $1 \#$ after the isolation reconstruction project is mainly caused by the following points. First, the ventilation system in the south wing includes two sub-systems (Shaqu ventilation subsystem and Baijiapo ventilation subsystem), which use different ventilators as the ventilation power. The two ventilation systems are in parallel connection but are mutually independent in structure. Second, this isolation project closes one intake airway in parallel connection in the Shaqu ventilation system where upcast inclined shaft $1 \#$ increases the wind resistance. Finally, the upcast inclined shaft 1\# operates at nearly full load before the isolation reconstruction, but the isolation reconstruction project results in the unstable operation of the ventilator. Therefore, resistance in the ventilation roadways should be reduced to decrease power consumption of the ventilator and thus recover the ventilator at upcast inclined shaft 1 \# to normal working conditions.

After the reconstruction of mine ventilation system, main ventilator in upcast inclined shaft $1 \#$ is at the unstable working state and the simulated results during problem analysis are ineffective. Hence, resistance distribution in the ventilation system in the south wing was analysed by combining simulation data before the isolation. Before the isolation at the 
intersection of Shaqu ventilation system and Baijiapo ventilation system, the air supply in the air intake airway of the Shaqu system is $3642 \mathrm{~m}^{3} / \mathrm{min}$, including $486 \mathrm{~m}^{3} / \mathrm{min}$ air quantity returning to the Shaqu system directly through the mechanical chamber and $342 \mathrm{~m}^{3} / \mathrm{min}$ air quantity that enters into the standby working face and returns to the Shaqu system. Given the large wind resistance in this ventilation system, air quantity can only discharge to the ground surface through the Baijiapo system. The air quantity of the Shaqu ventilation system entering into the Baijiapo system is calculated as $2814 \mathrm{~m}^{3} / \mathrm{min}$. After the isolation, wind resistance in the air intake section and air return section of the Shaqu ventilation system could be decreased directly because of the limited roadway layout and ventilator load. Decreasing resistance only on the air-consumption route is reasonable. Main air-consumption points in the Shaqu ventilation system include the working face of coal districts 1,3 , and 4 as well as the excavation roadway in zone 9. They form the parallel connection ventilation network in terms of structure. Although wind resistance could be reduced by adjusting air consumption on the working face in coal districts 1,3 , and 4 and adjusting air quantity on the return airway, these adjustment measures are in the parallel connection and diagonal branch in the entire network. According to simulation verification, these adjustment measures can neither reduce resistance of the entire ventilation system significantly nor reduce the ventilator loads effectively.

On the basis of the long-term mine planning, the air flow short-circuit method of ventilation networks was proposed to reduce resistance. The adjusting air window in the concentrated return airway of the south 9 in coal district 9 is open, which causes short-circuit of some air flows. As a result, air flow enters the rise of rail and intake airway from the shaft mouth, and from the bottom, it enters the rise of return airway directly through the air window in the south 9. In this way, the resistance of the entire ventilation system could be reduced effectively. At the same time, air quantity reduction in the ventilation network caused by air flow short-circuit, which lies at the working face of coal districts 1,3 and 4 , could be eliminated by adjusting air quantity on the working face and increasing air supply.

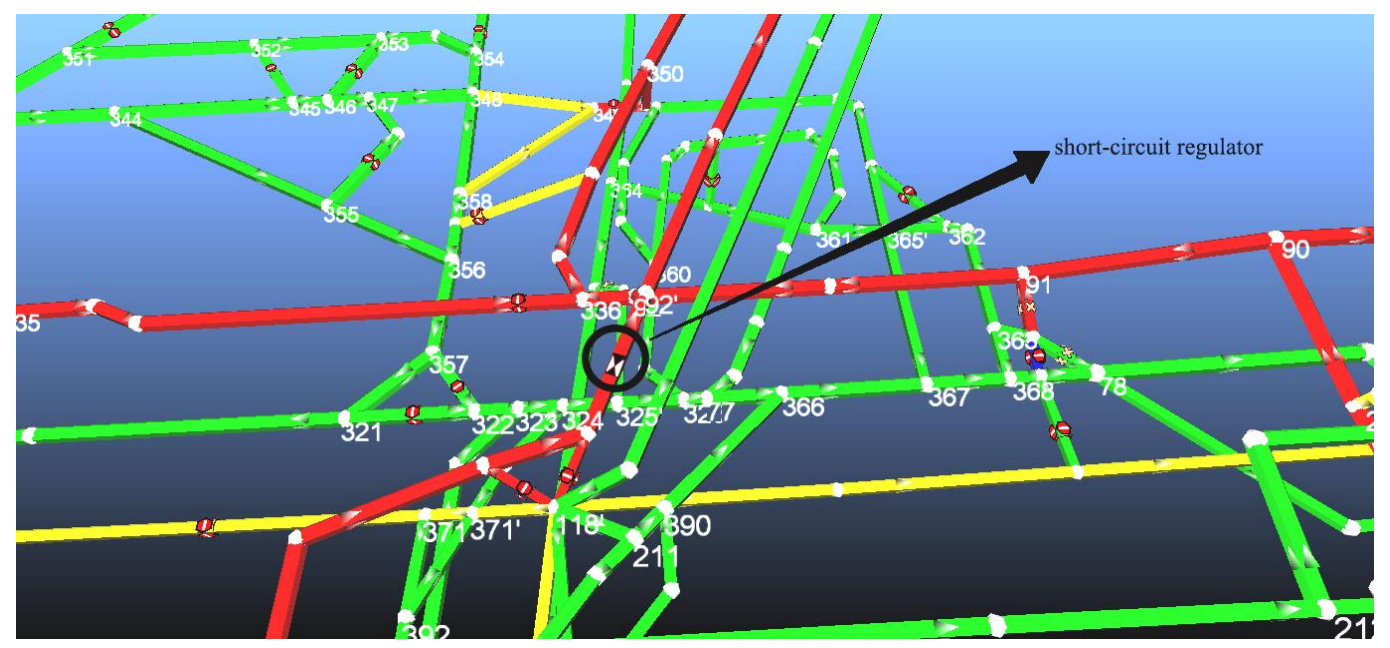

Figure 8: Ventilation door in the concentrated return airway of the south 9.

The simulation calculation shows that, after setting ventilation door 1 (Fig. 8), the resistance of the ventilation door in the concentrated return airway of south 9 reduces by 404 $\mathrm{Pa}$ and the air quantity in the roadway increases from the $1458 \mathrm{~m}^{3} / \mathrm{min}$ to $3444 \mathrm{~m}^{3} / \mathrm{min}$. These conditions can realize the goal of resistance reduction. The main ventilator in upcast inclined shaft $1 \#$ at the south wing can recover to normal working state. Resistances of the ventilation doors in the 14105 working face of coal district 1 (Fig. 9) and the 14301 working face of coal district 3 (Fig. 10) are reduced by 208 and $126 \mathrm{~Pa}$, respectively. As a result, air quantity of the working faces are increased to 1230 and $426 \mathrm{~m}^{3} / \mathrm{min}$, which are equal to those before the reconstruction. 


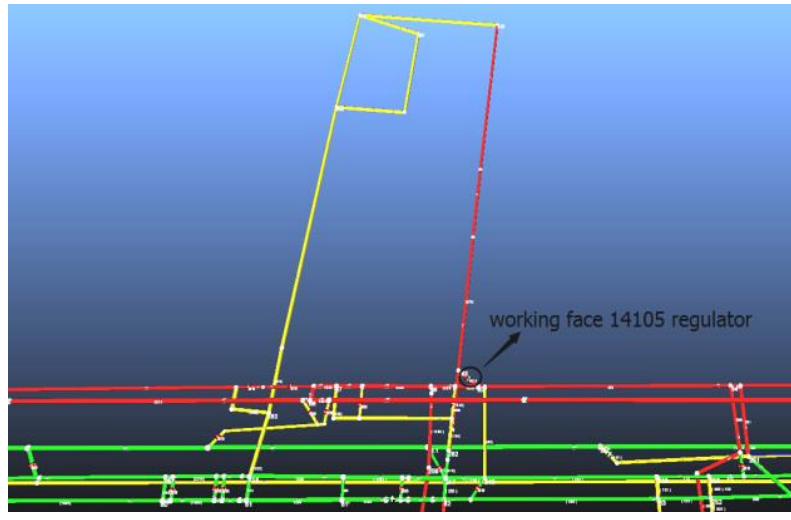

Figure 9: Adjustment in working face 14105.

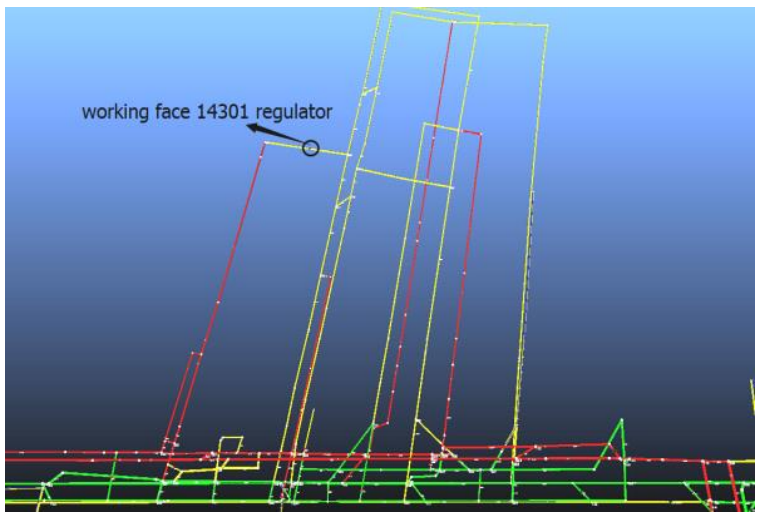

Figure 10: Adjustment in working face 14301.

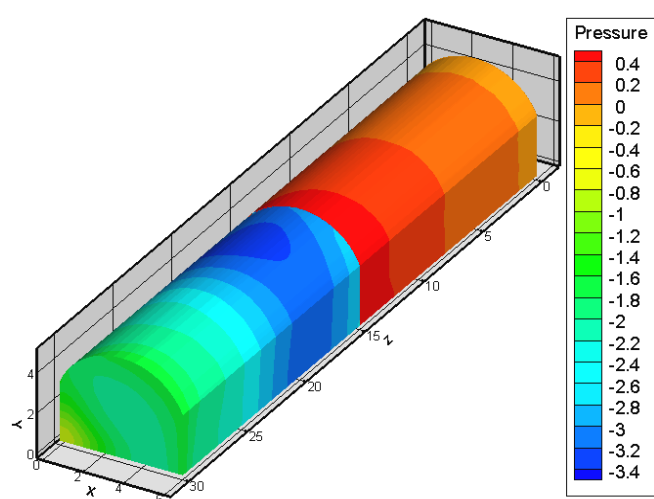

a)

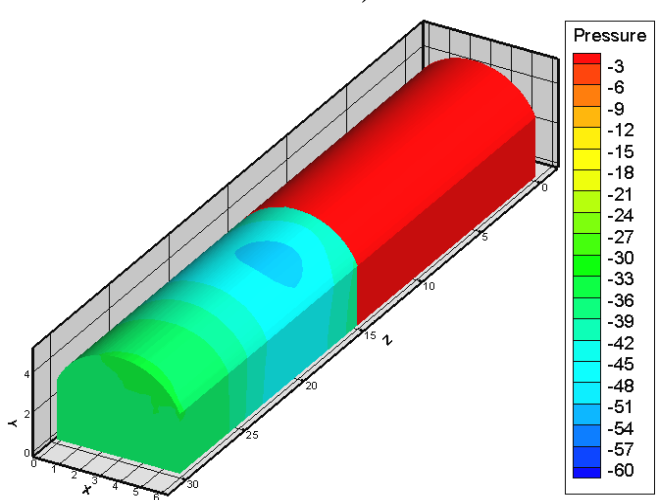

c)

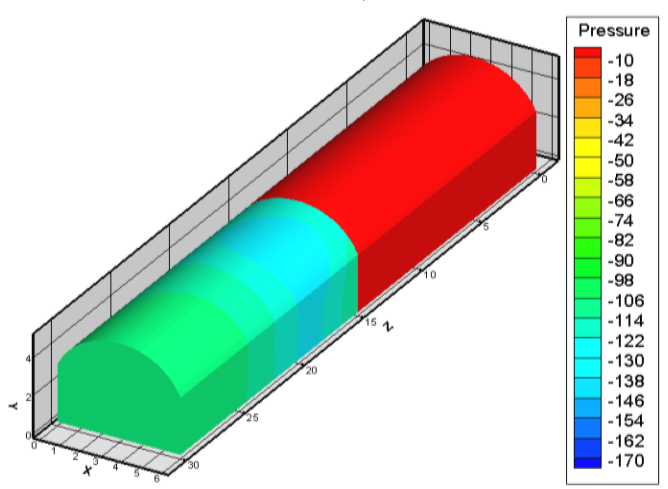

e)

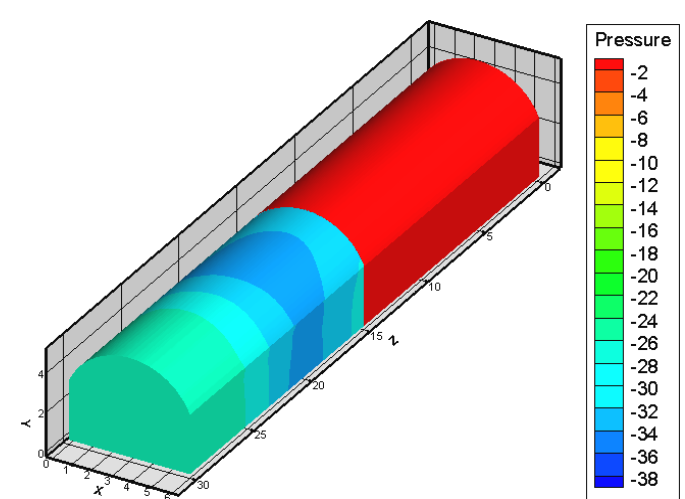

b)

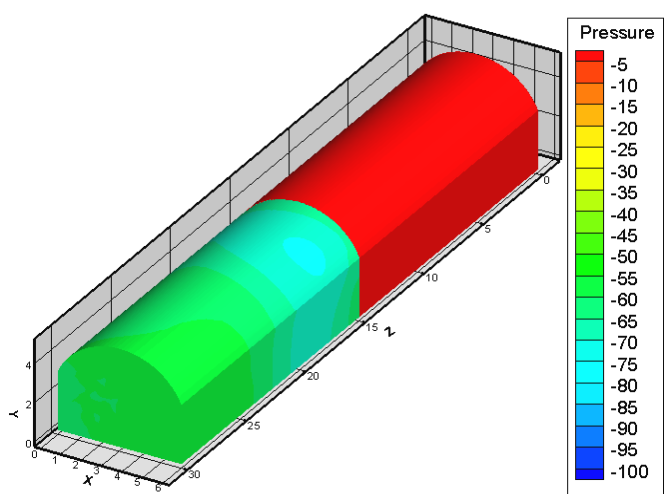

d)

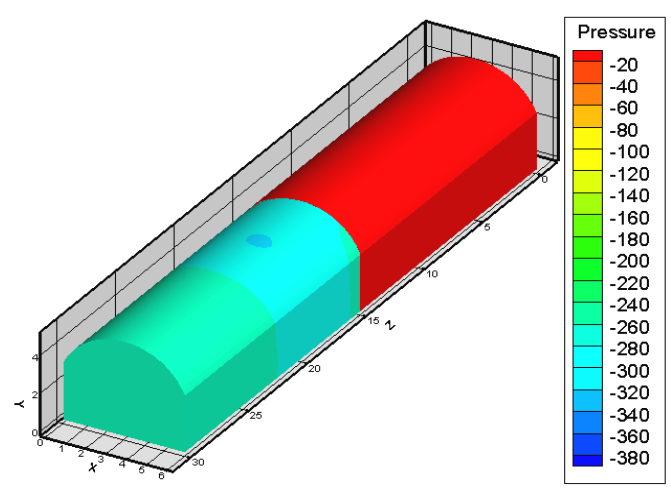

f)

Figure 11: Cloud of roadway pressure.

After the adjustment, the air quantity from the Shaqu system into the Baijiapo system reduces from $2814 \mathrm{~m}^{3} / \mathrm{min}$ to $1229 \mathrm{~m}^{3} / \mathrm{min}$ due to the resistance reduction in the Shaqu 
ventilation system. This condition verifies the effectiveness of the air flow short-circuit method in ventilation network. Air quantity of other working faces and air-consumption points in the south wing remain same owing to their structural position in the ventilation network.

After the simulation calculation, the wind resistance is $0.173 \mathrm{NS}^{2} / \mathrm{m}^{8}$ after regulating the ventilation door in the concentrated return airway in south 9. Under the control conditions of continuity equation and the momentum equation, the model entrance was set as the speed boundary condition in this study. Fig. 11 shows the pressure cloud of wind resistance in the roadway under different opening areas of air window with wind velocity of $1 \mathrm{~m} / \mathrm{s}$.

The window areas in Figs. $11 \mathrm{a}, \mathrm{b}, \mathrm{c}, \mathrm{d}$, e, and $\mathrm{f}$ are 9, 6, 5, 4, 3, and $2 \mathrm{~m}^{2}$, respectively. Fig. 11 shows the pressure distribution of the roadway when the wind velocity at the air intake is $1 \mathrm{~m} / \mathrm{s}$, and Table II presents the wind resistance of the roadway under different opening areas of the air window.

Table II: Window area and wind resistance of the roadway.

\begin{tabular}{|l|c|c|c|c|c|c|c|}
\hline \multicolumn{1}{|c|}{ Window area } & 9 & 6 & 5 & 4 & 3 & 2 & 1 \\
\hline Air Quantity $\left(\mathrm{m}^{3} / \mathrm{min}\right)$ & 26.67 & 26.67 & 26.67 & 26.67 & 26.67 & 26.67 & 26.67 \\
\hline Resistance $(\mathrm{N})$ & 4.0 & 37.9 & 62.6 & 103.1 & 161.6 & 352.2 & 1334.1 \\
\hline Wind Resistance $\left(\mathrm{NS}^{2} / \mathrm{m}^{8}\right)$ & 0.0056 & 0.0533 & 0.0880 & 0.1449 & 0.2272 & 0.4952 & 1.8840 \\
\hline
\end{tabular}

The mathematical equation between the opening area of air window and wind resistance of the roadway could be gained through linear fitting as follows:

$$
R=2.7268 \times S^{-2.398}
$$

The correlation coefficient is 0.9271 , which indicates a good linear correlation. $R$ is the wind resistance of the roadway $(\mathrm{N})$, and $S$ is the opening area of the air window $\left(\mathrm{m}^{2}\right)$. Fig. 12 shows the direct relationship between the opening area of air window and the roadway.

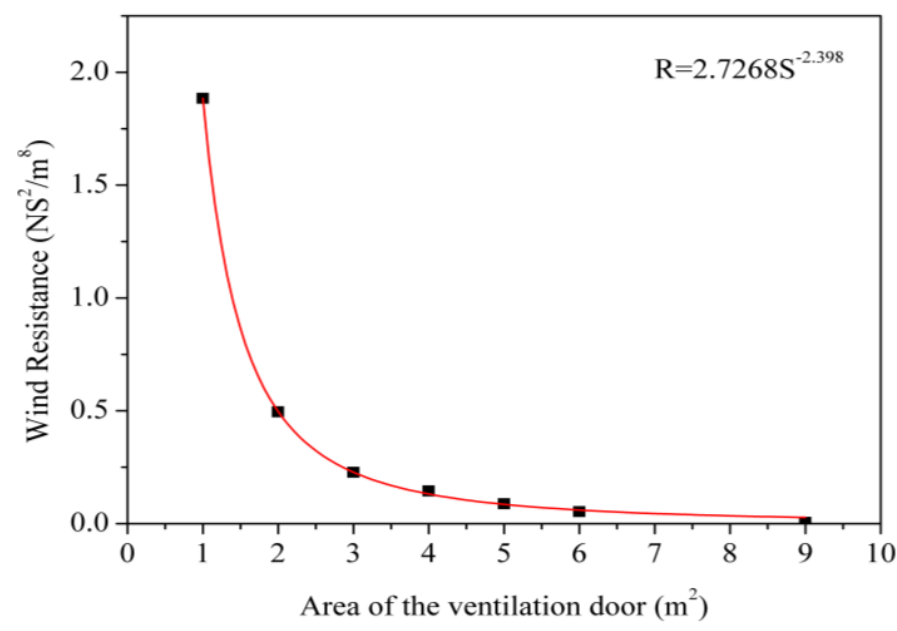

Figure 12: Relationship between wind resistance and window area in the roadway.

The calculation results indicate that the opening area of air window in the concentrated return airway should be at least $3.28 \mathrm{~m}^{2}$ to maintain normal and steady running of ventilators.

\section{CONCLUSIONS}

In order to increase the accuracy of studying the mine ventilation system reconstruction by the simulation technology, taking the reconstruction of ventilation system in Shaqu Coal Mine of China as an example, this study proposed the "calculation-feedback-correction" mechanism 
to correct previous simulation errors caused by replacing the wind resistance of unmeasured roadways with the wind resistance of the whole coal mine. Finally, the following conclusions are obtained:

(1) The 3D Ventsim ventilation system simulation model based on the "calculationfeedback-adjustment" mechanism can correct the simulation error caused by replacing the wind resistance of unmeasured roadways with that of the coal mine and reflect the current state of the mine ventilation system.

(2) Studying the ventilation system reconstruction of the Shaqu Mine by the 3D Ventsim ventilation system simulation model can accurately predict the air quantity changes in the main ventilators and air-consumption points in the ventilation system after the isolation reconstruction. The conclusion provides a valuable technological reference for the reconstruction and optimization of the mine ventilation system.

(3) The simulation results on mine ventilation system reconstruction and optimization show that the main ventilator in upcast inclined shaft $1 \#$ at the south wing run normally after the air flow short-circuit regulation and after setting the optimal opening area of air window. The air quantities on working face 14105 in coal district 1 and working face 14301 in coal district 3 reaches 1230 and $426 \mathrm{~m}^{3} / \mathrm{min}$, respectively; these values are equal to those before the isolation reconstruction. The mine ventilation system achieves the expected effect with reasonable ventilation parameters, and presents stable and reliable after the isolation reconstruction.

However, given the complicated conditions in most underground mines and the frequent changes in the ventilation system, the measurement accuracy of wind resistance may be influenced by various factors, such as humidity, temperature, wind speed, and record time. Thus, simulation calculation errors can occur in the ventilation system. Therefore, one important exploration in the future for the extensive application of the simulation system is to conduct real-time data monitoring and analysis by the data monitoring system based on the high-precision sensor. The current ventilation network optimization theory is established under the steady flow. Future studies can establish or expand the existing mathematical model to the ventilation network optimization under the unsteady flow field.

\section{ACKNOWLEDGEMENT}

This study was supported by the National Natural Science Foundation of China (51604024) and the Science and Technology Innovation Program (ZLY2015078).

\section{REFERENCES}

[1] Danko, G. L. (2013). Subsurface flow and transport process model for time dependent mine ventilation simulations, Transactions of the Institution of Mining \& Metallurgy: Section A, Vol. 122, No. 3, 134-144, doi:10.1179/147490013X13639459465691

[2] Wu, B.; Liu, X.; Wang, K. (2010). Reliability test of basic ventilation network data based on the simulation of ventilation network, Journal of Safety Science and Technology, Vol. 10, No. 2, 1620

[3] Hwang, I.-P.; Choi, H.-J.; Roh, J.-H.; Kim, J. (2012). A study on the airflow distribution in the diagonal ventilation circuit for the design of a high level radioactive waste repository, Tunnel and Underground Space, Vol. 22, No. 3, 173-180, doi:10.7474/TUS.2012.22.3.173

[4] Babu, V. R.; Maity, T.; Prasad, H. (2015). Energy saving techniques for ventilation fans used in underground coal mines - a survey, Journal of Mining Science, Vol. 51, No. 5, 1001-1008, doi: $10.1134 / \mathrm{S} 1062739115050198$

[5] Krawczyk, J.; Janus, J. (2014). Modeling of the propagation of methane from the longwall goaf, performed by means of a two-dimensional description, Archives of Mining Sciences, Vol. 59, No. 4, 851-868, doi:10.2478/amsc-2014-0059 
[6] Widiatmojo, A.; Sasaki, K.; Sugai, Y.; Suzuki, Y.; Tanaka, H.; Uchida, K.; Matsumoto, H. (2015). Assessment of air dispersion characteristic in underground mine ventilation: field measurement and numerical evaluation, Process Safety and Environmental Protection, Vol. 93, 173-181, doi:10.1016/j.psep.2014.04.001

[7] Torno, S.; Torano, J.; Ulecia, M.; Allende, C. (2013). Conventional and numerical models of blasting gas behaviour in auxiliary ventilation of mining headings, Tunnelling and Underground Space Technology, Vol. 34, 73-81, doi:10.1016/j.tust.2012.11.003

[8] Rusinski, E.; Moczko, P.; Odyjas, P.; Pietrusiak, D. (2014). Investigation of vibrations of a main centrifugal fan used in mine ventilation, Archives of Civil and Mechanical Engineering, Vol. 14, No. 4, 569-579, doi:10.1016/j.acme.2014.04.003

[9] Zhang, J. W.; Choi, W.; Ito, T.; Takahashi, K.; Fujita, M. (2016). Modelling and parametric investigations on spontaneous heating in coal pile, Fuel, Vol. 176, 181-189, doi:10.1016/ j.fuel.2016.02.059

[10] Cheng, J. W. A new verification method of mine ventilation system state based on selfadjustment of wind resistance, from http://cpquery.sipo.gov.cn/, accessed on 28-03-2013

[11] Deen, J. B. (1991). Field verification of shaft resistance equations, Proceedings of the $5^{\text {th }} U S$ Mine Ventilation Symposium, 647-655

[12] Zhang, P. (2011). Research of mine ventilation resistance calculation based on BP neural network, Proceedings: $20112^{\text {nd }}$ International Conference on Artificial Intelligence, Management Science and Electronic Commerce (AIMSEC), 3226-3229, doi:10.1109/AIMSEC.2011.6011339

[13] Si, J. H.; Chen, K. Y. (2012). Measuring airflow \& evaluating resistance model of the mine ventilation network based on Tikhonov regularization, Journal of China Coal Society, Vol. 37, No. 6, 994-998

[14] Li, Y.-C.; Liu, T.-Q.; Zhou, Y.; Chen, S.-L. (2015). Study of node pressure energy analytical method based on inversion from air volume to wind resistance, Journal of China Coal Society, Vol. 40, No. 5, 1076-1080

[15] Deng, F.; Liu, J. (2015). Study on numerical integral method for the resistance of excavation ventilation system in one tunnel with single ventilator, Journal of Safety Science \& Technology, Vol. 15, No. 8, 40-45

[16] Dziurzynski, W.; Krach, A.; Palka, T. (2015). A reliable method of completing and compensating the results of measurements of flow parameters in a network of headings, Archives of Mining Sciences, Vol. 60, No. 1, 3-24, doi:10.1515/amsc-2015-0001

[17] Li, M.; Zhang, X.-P.; Mao, S.-J.; Liu, Q.-S. (2009). Study of deep mining safety control decision making system, Procedia Earth and Planetary Science, Vol. 1, No. 1, 377-383, doi:10.1016/ j.proeps.2009.09.060

[18] Wang, K.; Jiang, S.; Ma, X.; Wu, Z.; Shao, H.; Zhang, W.; Cui, C. (2016). Numerical simulation and application study on a remote emergency rescue system during a belt fire in coal mines, Natural Hazards, Vol. 84, No. 2, 1463-1485, doi:10.1007/s11069-016-2538-z

[19] Habibi, A.; Kramer, R. B.; Gillies, A. D. S. (2015). Investigating the effects of heat changes in an underground mine, Applied Thermal Engineering, Vol. 90, 1164-1171, doi:10.1016/ j.applthermaleng.2014.12.066

[20] Develo, E.; Pillalamarry, M.; Garab, E. (2016). Improving the ventilation system at Rosh Pinah zinc mine, Journal of the Southern African Institute of Mining and Metallurgy, Vol. 116, No. 4, 301-305

[21] Jang, S.; Roh, J.; Kim, J. (2015). A study on the improvement of temperature environment for domestic deep coal mines, Journal of the Korean Society of Mineral and Energy Resources Engineers, Vol. 52, No. 1, 9-19

[22] Suvar, M.; Cioclea, D.; Gherghe, I.; Pasculescu, V. (2012). Advanced software for mine ventilation networks solving, Environmental Engineering and Management Journal, Vol. 11, No. $7,1235-1239$ 